\title{
Algoritma Backpropagation Neural Network dalam Memprediksi Harga Komoditi Tanaman Karet
}

\author{
Julius Rinaldi Simanungkalit a,1, Haviluddin Haviluddin a,2,* dan Herman Santoso Pakpahan a,3, \\ Novianti Puspitasari a,4 dan Masna Wati a,5 \\ ${ }^{a}$ Universitas Mulawarman, Jl. Kuaro I, Kampus Sempaja, Samarinda, Kalimantan Timur 75119 \\ ${ }^{1}$ simanungkalit100@gmail.com; ${ }^{2} h a v i l u d d i n @ u n m u l . a c . i d ;{ }^{3}$ pakpahan.herman891@gmail.com; \\ ${ }^{4}$ novianti_miechan@yahoo.com; ${ }^{5}$ masnawati.ssi@gmail.com \\ * corresponding author
}

\section{Kata Kunci: \\ Komoditas \\ Harga Karet \\ Prediksi \\ BPNN \\ MSE}

INFORMASI ARTIKEL

Dikirim: 11 Februari 2020

Diulas: 19 Februari 2020

Direvisi: 10 April 2020

Diterbitkan: 27 April 2020

\section{ABSTRAK}

Sektor perkebunan tanaman karet merupakan salah satu komoditas unggulan Provinsi Kalimantan Timur yang memberikan kontribusi besar terhadap ekspor nonmigas. Saat ini, harga tanaman karet di dunia semakin bersaing. Tujuan penulisan artikel ini adalah melakukan prediksi harga tanaman karet dimana hasil prediksi digunakan sebagai acuan instansi pemerintahan dan perusahaan dalam mengambil suatu kebijakan dan penyusunan rencana kerja. Penelitian ini menerapkan algoritma Backpropagation Neural Network (BPNN) dalam memprediksi harga tanaman karet. Sebanyak 60 bulan atau periode tahun 20142018 yang berasal dari Dinas Perkebunan Provinsi Kalimantan Timur telah digunakan untuk dianalisa. Berdasarkan hasil pengujian, parameter algoritma BPNN dengan rasio data 4:1, model arsitektur 5-10-10-10-1, fungsi pembelajaran trainlm, learning rate sebesar 0.5, toleransi error sebesar 0.01 dan epoch sebesar 1000 telah mendapatkan akurasi baik dengan nilai mean square error (MSE) sebesar 0.00015464. Hasil penelitian memperlihatkan bahwa algortima BPNN dapat dijadikan salah satu alternatif metode peramalan.

\section{Keywords: \\ Commodity \\ Rubber prices \\ Prediction \\ BPNN \\ MSE}

This is an open access article under the CC-BY-SA license.

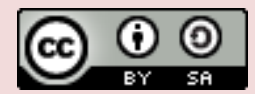

\section{Pendahuluan}

Indonesia merupakan negara penghasil karet terbesar di dunia setelah Thailand. Karet merupakan komoditas perkebunan yang memiliki peran cukup stategis dalam perekonomian bangsa. Produksi karet Indonesia cukup besar dalam pasar Internasional Sehingga, dalam neraca perdagangan negara, sektor perkebunan karet merupakan penyumbang devisa negara kedua terbesar setelah kelapa sawit. Karet merupakan komoditi yang tingkat permintaan dan produksinya sering mengalami peningkatan yang signifikan setiap waktu. Pada tahun 2002, volume ekspor sebesar 1,496 juta ton atau senilai USD 1038 juta, sedangkan pada tahun 2010 meningkat sebesar 2.35 juta ton atau 57\% atau senilai USD 7330 juta [1], [2]. Provinsi Kalimantan Timur merupakan salah satu provinsi yang memiliki pertumbuhan perkebunan karet yang cukup baik. Pada tahun 2018, total luas lahan perkebunan tanaman karet mencapai 115.082 hektar (ha) terdiri dari Perkebunan Rakyat (PR) sebesar 92.354 ha, Perkebunan Besar Swasta (PSR) sebesar 22.329 ha, dan Perkebunan Besar 
Negara (PBN) sebesar 339 ha yang tersebar di 10 kota/kabupaten. Dari luas lahan tersebut, produksi perkebunan tanaman karet sebanyak 57.389 ton dan produktivitas sebanyak $1.220 \mathrm{~kg} / \mathrm{ha}$ dengan harga rata-rata komoditi tanaman karet untuk tahun 2018 sebesar Rp. 6.800 per kilogram. Sedangkan, Tenaga Kerja Perkebunan (TKP) sebanyak 64.825 [2][3].

Peneliti, Rofiq, menggunakan metode Backpropagation Neural Network (BPNN) untuk memprediksi komoditas strategis pertanian cabai. Tingkat akurasi yang didapatkan dari rata-rata error perbandingan data aktual dan data peramalan (MAPE) yaitu sebesar 16.193\% [4]. Sedangkan, menggunakan metode BPNN berbasis Particle Swarm Optimization (PSO) untuk memprediksi harga karet spesifik teknis. Hasil pengujian menggunakan BPNN saja menghasilkan nilai root mean square error (RSME) sebesar 0.043 sedangkan dengan menggunakan model BPNN yang dioptimasi dengan PSO menghasilkan nilai RSME yang lebih kecil yaitu 0.040 [5]. Lebih lanjut, menggunakan metode BPNN untuk memprediksi harga saham (IHSG). Proses prediksi menghasilkan tingkat keakuratan sebesar 99.98\% dan MSE sebesar 0.9915 [6]. Penelitian prediksi harga komoditi kopi arabika menggunakan algoritma K-Nearest Neighbor (KNN) yang dikombinasikan dengan metode Backward Elimination (BE) untuk mendapatkan akurasi prediksi yang baik telah dilakukan. Hasil eksperimen penelitian ini menunjukkan kombinasi algoritma tersebut dapat memperkecil nilai error, dibandingkan dengan KNN tanpa seleksi fitur dan BPNN, BPNN dengan BE [7]. Selanjutnya, prediksi harga komoditi jagung menggunakan algoritma K-Nearest Neighbor (KNN) berbasis Particle PSO. Hasil eksperimen penelitian ini menunjukkan bahwa algoritma ini menghasilkan nilai RMSE 0.06 yang berarti akurasi prediksi cukup baik [8].

Para peneliti telah memperlihatkan berbagai algoritma kecerdasan buatan yang digunakan untuk melakukan prediksi, klasifikasi, cluster dalam berbagai bidang seperti pertanian [9], [10], kesehatan [11], perbankan [12], keteknikan [13], [14] dan lain-lain. Hal ini menunjukkan bahwa algoritma cerdas menjadi pilihan bagi para peneliti untuk melakukan analisa [15]. Tujuan penelitian ini adalah menerapkan algoritma kecerdasan buatan yaitu BPNN untuk mendapatkan hasil prediksi harga karet secara akurat. Artikel ini terdiri dari motivasi penulisan pada bagian Pendahuluan. Bagian kedua, metodologi BPNN dijelaskan dengan detail. Bagian ketiga, menjelaskan hasil dan analisa pengolahan data dengan kedua metode tersebut. Bagian terakhir, kesimpulan yang diperoleh.

\section{Metode}

Bagian ini menjelaskan dengan detail metode BPNN, pengukuran hasil simulasi prediksi dan data yang digunakan dalam penelitian ini.

\section{A. Backpropagation Neural Network}

Metode Backpropagation Neural Network (BPNN) pertama kali diperkenalkan oleh Paul Werbos pada tahun 1974, kemudian dikemukakan kembali oleh David Parker di tahun 1982 dan kemudian dipopulerkan oleh Rumelhart dan McCelland pada tahun 1986. Pada Algoritma BPNN arsitektur jaringan menggunakan jaringan multilayer [16 -19]. Secara prinsip, arsitektur BPNN terdiri dari tiga layer, yaitu input layer, hidden layer dan output layer. Pada input layer tidak terjadi proses komputasi, namun pada input layer terjadi pengiriman sinyal input $X$ ke hidden layer. Pada hidden dan output layer terjadi proses komputasi terhadap bobot dan bias dan dihitung pula besarnya output dari hidden dan output layer tersebut berdasarkan fungsi aktivasi tertentu. Adapun, fungsi aktivasi biasanya digunakan sigmoid biner dengan output [0-1]. Flowchart BPNN dapat dilihat pada Gambar 1.

Langkah-langkah yang perlu dilakukan untuk pelatihan BPNN adalah:

1) Inisialisasi bobot dengan bilangan nilai acak kecil.

2) Selama kondisi berhenti tidak terpenuhi, kerjakan langkah $3-8$

Tahap 1: Umpan Maju (Feed forward)

3) Tiap unit masukan $\left(x_{i}, i=1, \ldots, n\right)$ menerima isyarat masukan $x_{i}$ dan diteruskan ke unit-unit tersembunyi (hidden layer).

4) Tiap unit tersembunyi $\left(z_{j}, j=1, \ldots, p\right)$ menjumlahkan bobot sinyal input dengan persamaan (1).

$$
Z_{i n_{j k}}=v_{0 j}+\sum_{i=1}^{n} x_{i} v_{i j}
$$

Dimana, $Z$ adalah neuron hidden; $v_{0 j}$ adalah bobot bias neuron input ke- $j ; x_{i}$ adalah neuron input ke- $i$; $v_{i j}$ adalah bobot neuron input ke neuron hidden.

Dengan menerapkan fungsi aktivasi yang dihitung dengan persamaan (2).

$$
Z_{j}=f\left(Z_{i n_{j}}\right)
$$

Dimana, $Z_{j}$ adalah unit ke-j pada lapisan tersembunyi; $Z_{i n_{j}}$ adalah keluaran untuk unit $Z_{j}$ Misal, fungsi aktivasi yang digunakan yaitu sigmoid dengan persamaan (3). 


$$
Y=f(x)=\frac{1}{1+e^{-x}}
$$

Dan mengirimkan isyarat ini kesemua unit pada unit keluaran.

5) Tiap unit keluaran $\left(y_{k}, k=1, \ldots, m\right)$ mejumlahkan isyarat masukan berbobot dengan menggunakan persamaan (4).

$$
Y_{i n_{k}}=w_{0 k}+\sum_{k=1}^{p} z_{j} w_{j k}
$$

Dimana, $Y_{i n_{k}}$ adalah keluaran untuk unit $y_{k} ; w_{0 k}$ adalah bobot bias untuk neuron hidden ke- $k ; z_{j}$ adalah unit ke $-j$ pada lapisan tersembunyi; $w_{j k}$ adalah bobot neuron hidden ke neuron output.

Dengan menerapkan fungsi aktivasi yang dihitung dengan persamaan (5).

$$
Y_{k}=f\left(Y_{i n_{k}}\right)
$$

Dimana, $Y_{i n_{k}}$ adalah keluaran untuk unit $Y_{k}$.

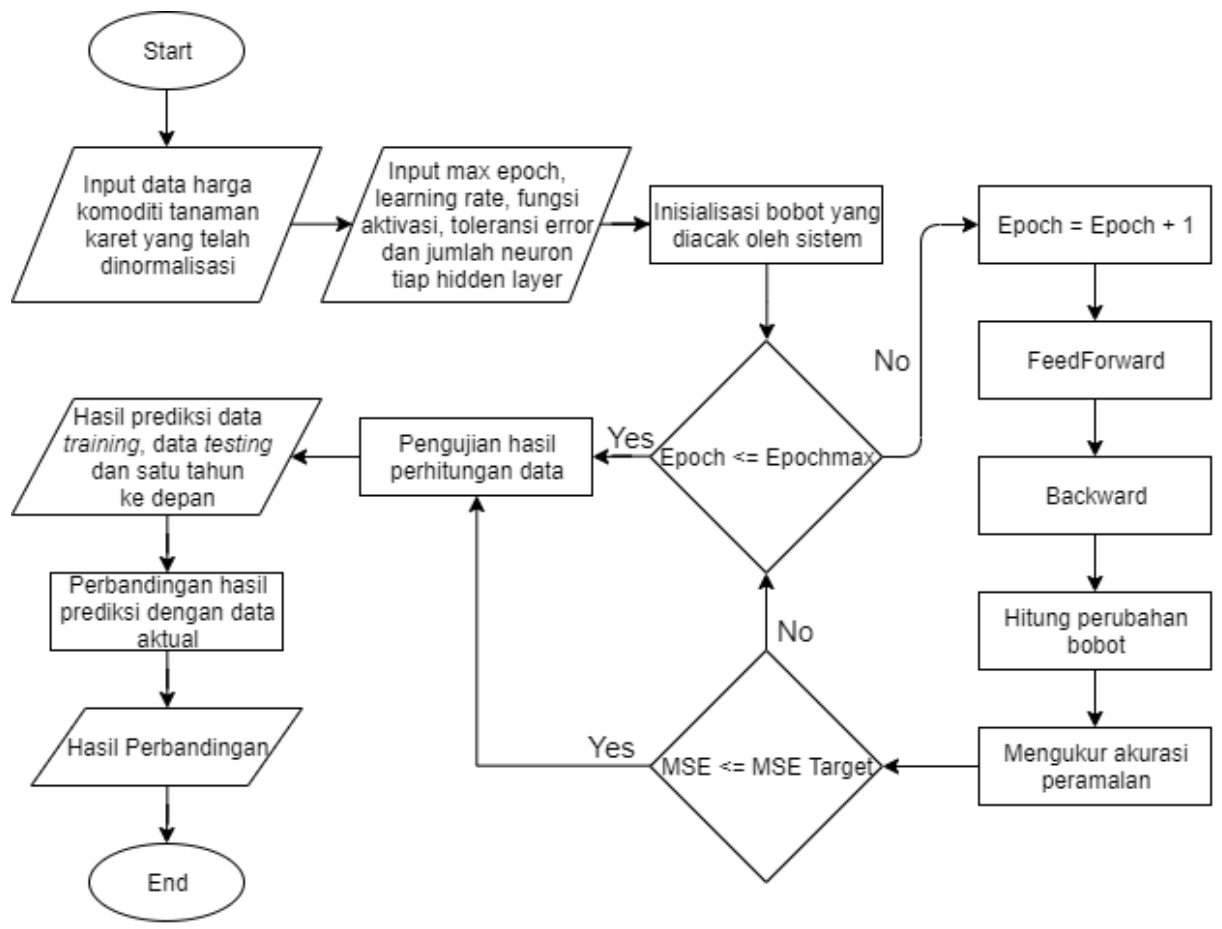

Gambar 1. Flowchart algortima BPNN

Tahap 2: Perambatan Galat Mundur (Backward)

6) Tiap unit keluaran $\left(y_{k}, k=1, \ldots ., m\right)$ menerima pola pelatihan masukannya. Hitung galat (error) setiap layer dengan persamaan (6).

$$
\delta_{k}=\left(t_{k}-y_{k}\right) f^{\prime}\left(y_{i n_{k}}\right)
$$

Dimana, $\delta_{k}$ adalah faktor koreksi bobot $w_{j k} ; t$ adalah target; $y_{k}$ adalah neuron output ke-k; $y_{i n_{k}}$ adalah keluaran untuk unit $y_{k}$.

Hitung koreksi bobot dan bias-nya dengan persamaan (7).

$$
\begin{aligned}
& \Delta w_{j k}=\alpha \delta_{k} x_{j} \\
& \Delta w_{0 k}=\alpha \delta_{k}
\end{aligned}
$$

Dimana, $\Delta w_{j k}=$ adalah selisih antara $w_{j k}(t)$ dengan $w_{j k}(t+1) ; \Delta w_{0 k}$ adalah bobot bias untuk neuron hidden ke- $k ; \alpha$ adalah learning rate; $\delta_{k}$ adalah faktor koreksi bobot $w_{j k} ; x$ adalah input.

7) Tiap unit tersembunyi $\left(z_{j}, j=1, \ldots \ldots, p\right)$ menjumlahkan delta masukannya (dari unit-unit yang berada pada lapisan atasannya) dengan persamaan (8). 


$$
\delta_{i n_{j}}=\sum_{k=1}^{m} \delta_{k} w_{j k}
$$

Dimana, $\delta_{k}$ adalah faktor koreksi bobot $w_{j k} ; w_{j k}$ adalah bobot neuron hidden ke neuron output.

Hitung galat (error) setiap layer dengan persamaan (9).

$$
\delta_{j}=\delta_{i n_{j}} f\left(x_{i n_{j}}\right)
$$

Dimana, $\delta_{j}$ adalah faktor koreksi bobot $v_{i j} ; \delta$ adalah faktor koreksi; $x$ adalah input.

Hitung koreksi bobot dan bias-nya dengan persamaan (10).

$$
\Delta v_{i j}=\alpha \delta_{j} x_{i}
$$

Dimana, $\Delta v_{i j}$ adalah bobot neuron input ke neuron hidden; $\alpha$ adalah learning rate; $\delta_{j}$ adalah faktor korelasi bobot $v_{i j} ; x_{i}$ adalah neuron input $\mathrm{ke}-i$.

\section{Tahap 3: Perbaiki bobot dan bias (Update Weight)}

8) Tiap unit keluaran $\left(y_{k}, k=1, \ldots \ldots, m\right)$ memperbaharui bobot dan bias $(j=0,1, . . p)$ dihitung dengan persamaan (11).

$$
w_{j k}(\text { baru })=w_{j k}(\operatorname{lama})+\Delta w_{j k}
$$

Dimana, $w_{j k}$ adalah bobot neuron hidden ke neuron output; $\Delta w_{j k}$ adalah selisih bobot neuron hidden ke neuron output.

Tiap unit tersembunyi $\left(z_{j}, j=1, \ldots, p\right)$ memperbaharui bobot dan bias-nya $(i=0,1, . . n)$ dihitung dengan persamaan (12).

$$
v_{i j}(\text { baru })=v_{i j}(\operatorname{lama} a)+\Delta v_{i j}
$$

Dimana, $v_{i j}$ adalah bobot neuron input ke neuron hidden; $\Delta v_{i j}$ adalah selisih bobot neuron input ke neuron hidden.

9) Uji syarat berhenti.

\section{B. Akurasi Prediksi}

Dalam penelitian ini, metode Mean Squared Error (MSE) untuk mengevaluasi kesalahan peramalan pada setiap periode dan membaginya dengan jumlah periode peramalan telah digunakan [20]. Adapun rumus untuk melakukan perhitungan pengukuran akurasi MSE dapat dilihat dalam persamaan (13).

$$
M S E=\frac{1}{n} \sum_{i=1}^{n}\left(\Upsilon_{i}-\hat{\Upsilon}_{i}\right)^{2}
$$

Dimana, $\Upsilon_{i}$ adalah nilai aktual; $\widehat{\Upsilon}_{l}$ nilai prediksi; $n$ jumlah periode atau target.

\section{Sampel Data}

Dalam penelitian ini, data harga karet dari Januari 2014 hingga Desember 2018 atau sebanyak 60 dataset yang telah diperoleh dari Dinas Perkebunan Provinsi Kalimatan Timur telah digunakan. Tabel 1 menunjukkan Dataset data pelatihan yang telah dinormalisasi dalam jarak (range) 0,1-0,9 menggunakan persamaan (14).

$$
X^{\prime}=\frac{0.8(X-b)}{(a-b)}+0.1
$$

Dimana, $X^{\prime}$ adalah data hasil normalisasi; $X$ adalah data aktual; $a$ adalah nilai maksimum data aktual; $b$ adalah nilai minimum data aktual. Gambar 2 menunjukkan pola data harga tanaman karet dalam periode tersebut.

Kemudian dilakukan proses perhitungan prediksi dengan kedua metode tersebut. Hasil prediksi didenormalisasi untuk mendapatkan hasil prediksi ke bentuk semula. Adapun rumus untuk melakukan denormalisasi data dapat dilihat dalam persamaan (15).

$$
X=\frac{\left(X^{\prime}-0,1\right)(b-a)+0,8 a}{0,8}
$$


Tabel 1. Data Harga Komoditi Tanaman Karet Periode 2014-2018

\begin{tabular}{l|c|c|c|c|c}
\hline \multirow{2}{*}{ Bulan } & \multicolumn{5}{|c}{ Tahun } \\
\cline { 2 - 6 } & $\mathbf{2 0 1 4}$ & $\mathbf{2 0 1 5}$ & $\mathbf{2 0 1 6}$ & $\mathbf{2 0 1 7}$ & $\mathbf{2 0 1 8}$ \\
\hline Januari & 0.78648406 & 0.23237539 & 0.12658285 & 0.43767400 & 0.36115851 \\
Februari & 0.90000000 & 0.18208352 & 0.11508756 & 0.57436013 & 0.36115851 \\
Maret & 0.68123035 & 0.18747194 & 0.10000000 & 0.47754827 & 0.36115851 \\
April & 0.52604401 & 0.17831163 & 0.11670409 & 0.36169735 & 0.27135159 \\
Mei & 0.49622811 & 0.21746744 & 0.16142793 & 0.22806466 & 0.27135159 \\
Juni & 0.46192187 & 0.20399641 & 0.15711720 & 0.12514594 & 0.27135159 \\
Juli & 0.31697351 & 0.22914234 & 0.17148630 & 0.15047149 & 0.27135159 \\
Agustus & 0.21082173 & 0.14418500 & 0.11580602 & 0.18675348 & 0.27135159 \\
September & 0.33062416 & 0.12819937 & 0.11059722 & 0.24027840 & 0.27135159 \\
Oktober & 0.27242928 & 0.21243826 & 0.12927705 & 0.27871576 & 0.39708128 \\
November & 0.29470139 & 0.20740907 & 0.17256399 & 0.27745846 & 0.39708128 \\
Desember & 0.22914234 & 0.23740458 & 0.24979793 & 0.27997306 & 0.39708128 \\
\hline
\end{tabular}

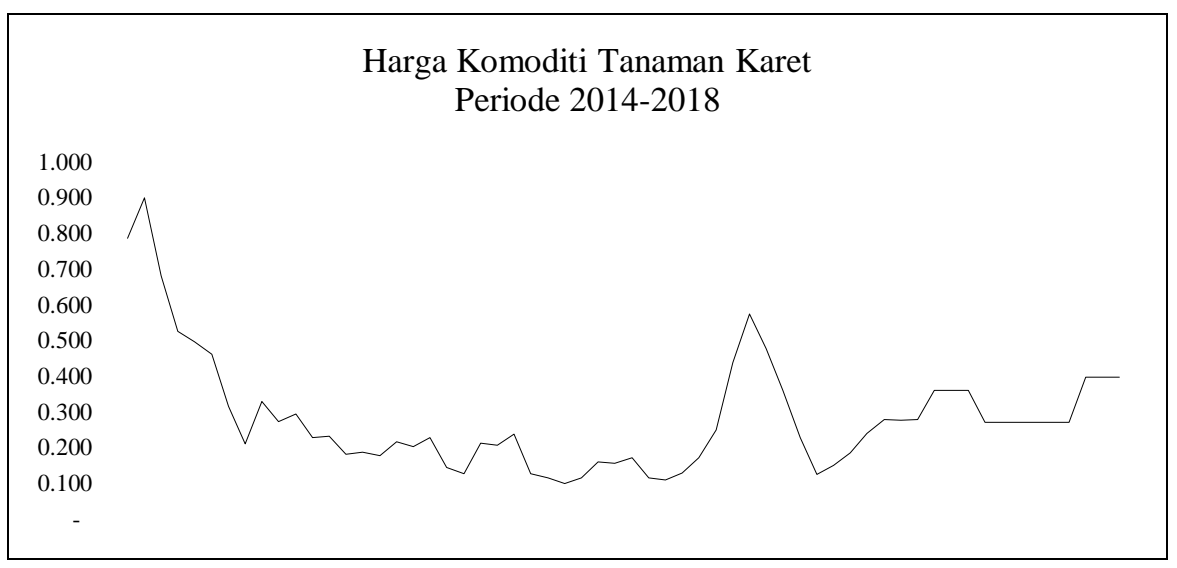

Gambar 2. Harga komoditi tanaman karet 2014-2018

\section{Hasil dan Pembahasan}

Bagian ini menjelaskan hasil temuan pengujian dan analisa metode BPNN dalam melakukan prediksi harga karet.

Pembagian data aktual sebagai data training dan data testing untuk mendapatkan hasil perbandingan yang baik telah dilakukan. Dalam percobaan ini, rasio data training dan data testing yaitu 4:1 dan 3:2 telah dilakukan. Rasio data 4:1 dengan pembagian data training dari tahun 2014-2017 atau 48 bulan dan data testing tahun 2018 atau 12 bulan. Sedangkan rasio data 3:2 dengan pembagian data training dari tahun 2014-2016 atau 36 bulan dan data testing tahun 2017-2018 atau 24 bulan telah diimplementasikan. Dalam percobaan ini variabel-variabel BPNN yang telah diimplementasikan dapat dilihat pada Tabel 2.

Tabel 2. Variabel BPNN

\begin{tabular}{l|l|l|l}
\hline \multicolumn{1}{c|}{ Variabel } & \multicolumn{1}{c}{ Nilai } \\
\hline \multirow{3}{*}{ Hidden Layer } & \multicolumn{1}{|c}{ Hidden Layer } & \multicolumn{1}{c}{ Architectures } \\
\cline { 2 - 4 } & 2 & 44 & $5-4-4-1$ \\
& 2 & 77 & $5-7-7-1$ \\
& 3 & 555 & $5-5-5-5-1$ \\
Fungsi Pembelajaran & 3 & 101010 & $5-10-10-10-1$ \\
Learning Rate & \multicolumn{2}{|}{ trainlm, traingd, traingdx Layer } \\
Toleransi Error & $0.1,0.3,0.5,0.7$ & \\
Max Epoch & 0.01 & 1000 \\
\hline
\end{tabular}

Tabel 3 menunjukkan bahwa berdasarkan percobaan, parameter BPNN dengan rasio data 4:1, model arsitektur 5-10-10-10-1, fungsi pembelajaran trainlm, learning rate sebesar 0.5, toleransi error sebesar 0.01 dan epoch sebesar 1000 telah mendapatkan akurasi baik dengan nilai MSE sebesar 0.00015464. Sedangkan, parameter BPNN dengan rasio data 3:2, model arsitektur 5-10-10-10-1, fungsi pembelajaran trainlm, learning rate sebesar 0.5 , toleransi error sebesar 0.01 dan epoch sebesar 1000 telah mendapatkan akurasi baik dengan nilai MSE sebesar 0.00148924. Dimana, rasio data 4:1 lebih baik dibandingkan 3:2. Hal ini menunjukkan bahwa pembagian data training dan data testing telah mempengaruhi tingkat akurasi. 
Tabel 3. Akurasi Metode BPNN

\begin{tabular}{|c|c|c|}
\hline \multirow{2}{*}{ Algoritma } & \multicolumn{2}{|c|}{ Rasio Data } \\
\hline & $4: 1$ & $3: 2$ \\
\hline BPNN & 0.00015464 & 0.00148924 \\
\hline
\end{tabular}

Hasil prediksi harga karet tahun 2019 dengan menggunakan rasio 4:1 dan 3:2 diberikan pada Tabel 4 dan pola harga dapat dilihat pada Gambar 3.

Tabel 4. Hasil Prediksi Harga Karet Tahun 2019

\begin{tabular}{l|c|c}
\hline \multirow{2}{*}{\multicolumn{1}{c|}{ Bulan }} & \multicolumn{2}{c}{ BPNN } \\
\cline { 2 - 3 } & 4:1 & 3:2 \\
\hline Januari & Rp. 6503 & Rp. 6685 \\
\hline Februari & Rp. 6503 & Rp. 6685 \\
\hline Maret & Rp. 6503 & Rp. 6685 \\
\hline April & Rp. 7084 & Rp. 7196 \\
\hline Mei & Rp. 7084 & Rp. 7196 \\
\hline Juni & Rp. 7084 & Rp. 7196 \\
\hline Juli & Rp. 6505 & Rp. 6860 \\
\hline Agustus & Rp. 6505 & Rp. 6860 \\
\hline September & Rp. 6505 & Rp. 6860 \\
\hline Oktober & Rp. 6993 & Rp. 7194 \\
\hline November & Rp. 6993 & Rp. 7194 \\
\hline Desember & Rp. 6993 & Rp. 7194 \\
\hline
\end{tabular}

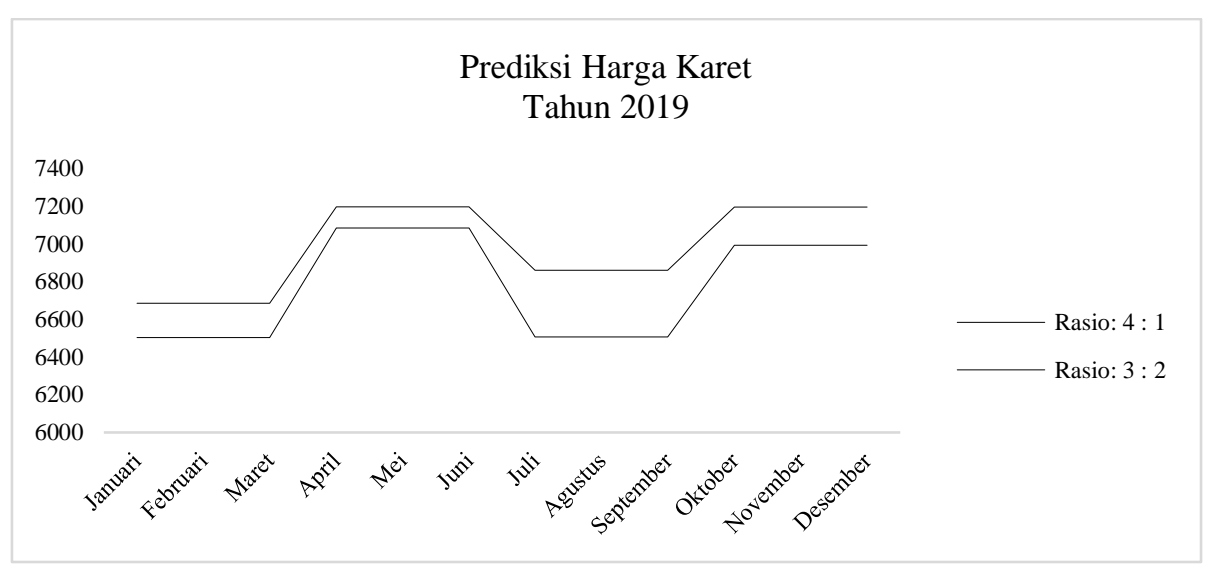

Gambar 3. Hasil Prediksi Harga Karet Tahun 2019

\section{Kesimpulan dan saran}

Analisa prediksi harga komoditi tanaman karet di Provinsi Kalimantan Timur dengan menggunakan metode Backpropagation Neural Network (BPNN) telah diimplementasikan. Berdasarkan hasil percobaan, metode BPNN dengan rasio data 4:1, model arsitektur 5-10-10-10-1, fungsi aktivasi trainlm, learning rate sebesar 0.5, toleransi error sebesar 0.01 dan epoch sebesar 1000 telah mendapatkan tingkat kesalahan prediksi yang cukup baik dengan nilai MSE sebesar 0.00015464. Dari hasil pengujian kedua metode, menunjukkan bahwa metode BPNN dapat menjadi alternatif dalam memprediksi harga komoditi tanaman karet di Provinsi Kalimantan Timur. Penelitian berikutnya dapat menggunakan metode prediksi lainnya untuk meningkatkan nilai prediksi saat ini.

\section{Daftar Pustaka}

[1] K. Dirjen Kerjasama Industri Internasional, "Perkembangan Kerjasama ASEAN di Sektor Industri (s.d. 2011)," 2012.

[2] D. Perkebunan, "Harga Komoditas Tanaman Karet," 2019. [Online]. Available: https://disbun.kaltimprov.go.id/kategori-download/harga-tbs-kelapa-sawit-tahun-2011-2017.

[3] S. D. Perkebunan, "Komoditas Karet 2011-2013,” 2012.

[4] M. A. Rofiq, Peramalan Komoditas Strategis Pertanian Cabai Menggunakan Metode Backpropagation Neural Network. 2017.

[5] M. A. Puspa, "Backpropagation Neural Network Berbasis Particle Swarm Optimization ntuk Prediksi Harga Karet Spesifik Teknis," J. Teknosains, Vol. 10, Nomor 2, Juli-Desember 2016, hlm. 197 - 210, vol. Volume 10, pp. 197-210, 2016.

[6] A. J. P. Triyono, Andri Santoso, "Penerapan Metode Jaringan Syaraf Tiruan Backpropagation Untuk 
Meramalkan Harga Saham (IHSG),” J. Sist. Dan Inform., vol. Vol 11, No, pp. 165-172, 2016.

[7] A. Bode, "K-Nearest Neigbor dengan Feature Selection menggunakan Backward Elimination untuk Prediksi Harga Komoditi Kopi Arabika," Ilk. J. Ilm., 2017.

[8] M. E. Lasulika, "Prediksi Harga Komoditi Jagung Menggunakan K-NN dan Particle Swarm Optimization sebagai Fitur Seleksi,” Ilk. J. Ilm., 2017.

[9] I. Santoso, U. Effendi, and C. Fauziya, "Penerapan Jaringan Syaraf Tiruan Untuk Peramalan Permintaan Komoditas Karet di PT Perkebunan Nusantara XII Surabaya," J. Teknol. Pertan., vol. 8, no. 1, pp. 4654, 2007.

[10] S. Wolfert, L. Ge, C. Verdouw, and M. J. Bogaardt, "Big Data in Smart Farming - A review," Agricultural Systems. 2017.

[11]M. I. Jordan and T. M. Mitchell, "Machine learning: Trends, perspectives, and prospects," Science. 2015.

[12] T. Fischer and C. Krauss, "Deep learning with long short-term memory networks for financial market predictions," Eur. J. Oper. Res., vol. 270, no. 2, pp. 654-669, 2018.

[13]D. Rajasekar, C. Dhanamani, and S. K. Sandhya, "A Survey on Big Data Concepts and Tools," Int. J. Emerg. Technol. Adv. Eng., vol. 5, no. 2 February 2015, pp. 80-84, 2015.

[14]C. H. Fajardo-toro, J. Mula, and R. Poler, Engineering Digital Transformation. Springer International Publishing, 2019.

[15] S. Athey, "The Impact of Machine Learning on Economics," in The Economics of Artificial Intelligence: An Agenda, University of Chicago Press, 2018.

[16]H. Aini and H. Haviluddin, "Crude Palm Oil Prediction Based on Backpropagation Neural Network Approach," Knowl. Eng. Data Sci., 2019.

[17] M. Lehtokangas, "Modelling with constructive backpropagation," Neural Networks, 1999.

[18] Mislan, Haviluddin, S. Hardwinarto, Sumaryono, and M. Aipassa, "Rainfall Monthly Prediction Based on Artificial Neural Network: A Case Study in Tenggarong Station, East Kalimantan - Indonesia," in Procedia Computer Science, 2015.

[19] P. Purnawansyah, H. Haviluddin, H. J. Setyadi, K. Wong, and R. Alfred, "An Inflation Rate Prediction Based on Backpropagation Neural Network Algorithm," Int. J. Artif. Intell. Res., vol. 3, no. 2, p. 2019, 2019.

[20] R. Rojas, “The Backpropagation Algorithm,” in Neural Networks, 2011. 